\title{
Is that Beauty? Cody Choi
}

Sala de Exposiciones del Rectorado, Universidad de Málaga, y Sala Moreno Villa, Ayuntamiento de Málaga

Del 17 de diciembre de 2016 al 18 de febrero de 2017

\section{Cody Choi: geopoliticas del arte y subterfugios del yo}

El discurso de la Gran Teoría clásica de la belleza, con su cristalización en representaciones icónicas del sistema del arte occidental, sufrió un gran cuestionamiento con las vanguardias históricas de principios del siglo XX, favoreciéndose con ello una gran apertura hacia formas de arte procedentes de culturas no-occidentales. Paradójicamente, este hecho coincidiría en el tiempo con el inicio de la influencia de nuestro gran arte del pasado en esos territorios excéntricos a la tradición europea. Fue entonces cuando la Corea ocupada por Japón empezó a recibir el influjo indirecto de Occidente a través del filtro de su propio vecino opresor. Surge entonces un incipiente sistema del arte a imitación del occidental en el que los artistas empiezan a pintar desnudos al óleo, esculpir esculturas o, en ocasiones, referirse a su propia cultura con el lenguaje plástico occidental. Tras la liberación de Japón, las complejas interacciones y tensiones Oriente/Occidente se seguirán sintiendo intensamente en Corea del Sur, sobre todo por la presencia norteamericana en el país. A partir de los años ochenta, la influencia de las teorías postmodernas y en particular la teoría cultural postcolonial se dejará sentir en los artistas de dicha generación, ocupando entre ellos Cody Choi un lugar prominente tanto por su obra como por su producción teórica e intelectual desde su puesto en el sistema universitario coreano. Su reciente elección por el gobierno coreano para representar a su país en la Bienal de Venecia de 2017 confirma su posición de referencia en el escenario artístico coreano actual.

Cody Choi (Seúl, 1961) nace en el seno de una familia acomodada que se ve forzada a emigrar a Estados Unidos en los años ochenta, empezando allí una nueva vida en cuyo contexto el joven Choi emprende su formación artística, como él mismo confiesa, como una necesidad de encontrar un lenguaje que le permitiera comunicarse en un ambiente cultural hostil; una cultura que le acoge imponiéndole los cánones de su arte y sus discursos hegemónicos,

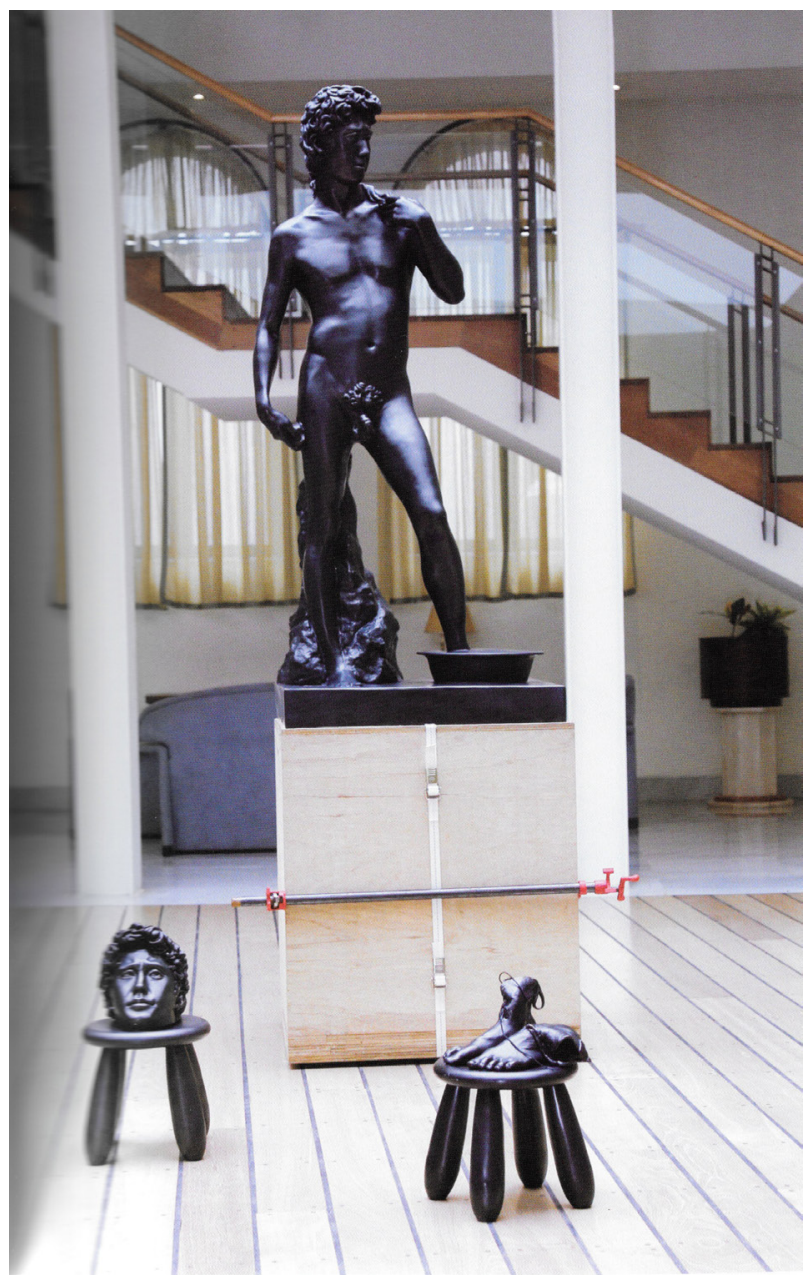

1. Cody's Legend vs. Freud's Shit Box, 1994-1995, bronce, madera, acero, 96x96x262 cm

contra el cual el propio Choi acabará por erigir su propia estrategia saboteadora como modo de encontrarse a sí mismo. Los trasvases y desencuentros culturales irán más lejos cuando, en 2003, Choi decide regresar a Seúl, donde finalmente volverá a sentirse desubicado tras haber vivido veinte años en Estados Unidos. De todo este largo periplo da cuenta la exposición retrospectiva Is that Beauty?, con más de setenta piezas, realizadas con los más diversos 


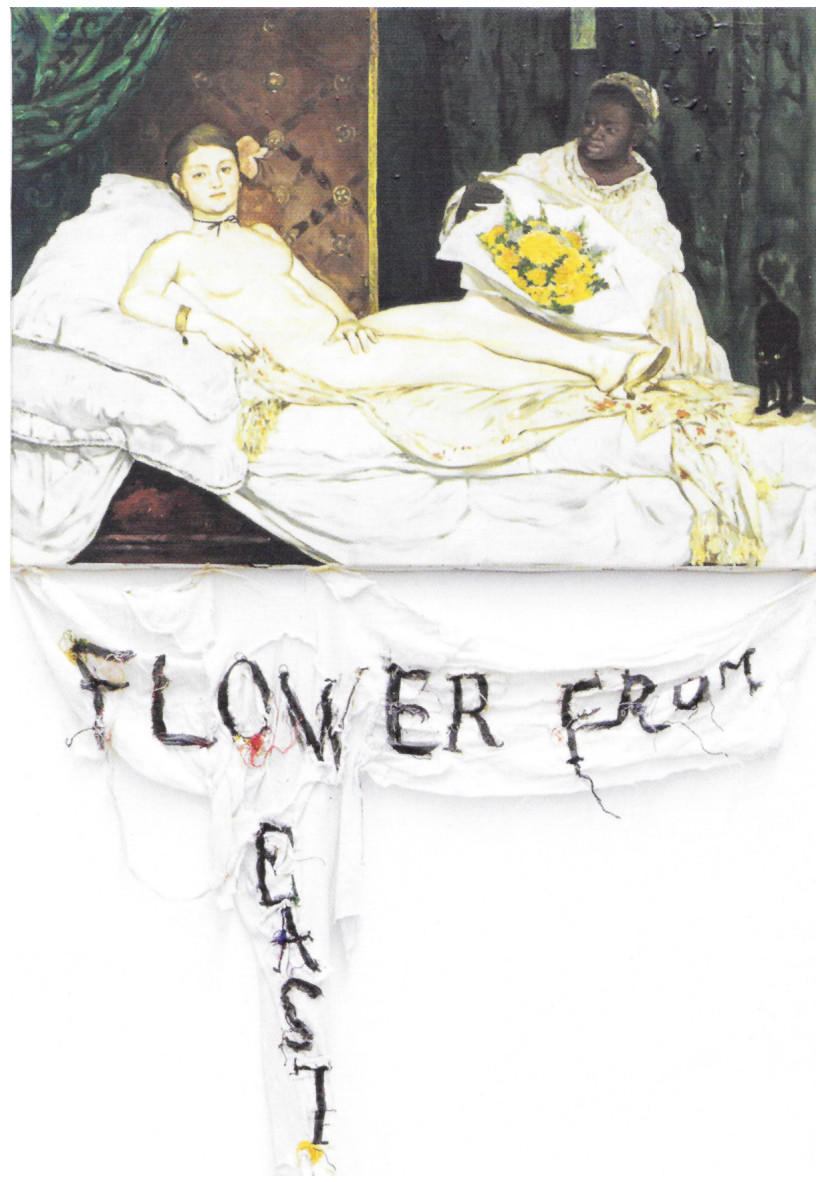

2. Episteme Sabotage-Flower From East, 2014, óleo sobre lienzo, tela, hilo, $66 \times 96 \mathrm{~cm}$

medios, comprendidas entre finales de los años ochenta hasta la actualidad y con un lenguaje conceptual de gran complejidad, inspirado en filósofos postestructuralistas y en nociones taoístas. Sin duda, por la magnitud y la relevancia de la obra expuesta, esta exposición, junto al catálogo que la acompaña, marcan un hito en el acercamiento a una figura clave del arte coreano actual.

En la Sala del Rectorado, una impresión fotográfica de gran tamaño en la que aparece el propio Choi de niño, tocando el violín con traje tradicional coreano [Neo-poscoIonian, 2013] testimonia ya esta primera experiencia de dominio cultural foráneo a través de las artes; otra instantánea borrosa de un niño desaparecido, procedente de la prensa coreana de la posguerra [Wanted Lost Child, 19861] nos permite adivinar en dicho rostro al propio Choi, en busca de su propia identidad. Pero antes habremos visto ya en el hall del Rectorado Cody's Legend vs. Freud's Shit Box (19941995) [1] otro ejercicio de auto-reconocimiento, siguiendo las prácticas apropiacionistas postmodernas, mediante una escultura de bronce de 96 centímetros de alto, que imita el David de Miguel Ángel, con el rostro del propio Choi, y con un pie introducido en una palangana coreana, elevada sobre un pedestal de madera contrachapada. Esta obra se dispone precedida de otras dos también en bronce: Self-portrait 1 (2014), la cabeza esculpida del propio Choi y Self-portrait 2 (2014) unos pies-zapatos magrittianos, ambas colocadas sobre sendos taburetes modelados a partir de un diseño comercial de lkea. Toda una declaración de intenciones, de mediados de los años noventa, sobre su propuesta particular para subvertir el poder hegemónico de los iconos del arte occidental, que proseguirá en nuestra visita a la exposición de diversas formas, en especial, con The Thinker (1996), remedo paródico de El pensador de Rodin, realizada con papel higiénico y pepto-bismol (un medicamento de color rosáceo contra la indigestión que Choi tomaba asiduamente en Estados Unidos). Una horadación en el pedestal de madera contrachapada alude a la posibilidad (que el artista llevó a cabo a modo de performance en los años noventa) de introducir el trasero en posición de defecar: un modo irreverente de señalar, mediante una pose similar a la rodiniana, la indigestión que el arte occidental le producía al tiempo que alude al acto creador como producción/proyección en un sentido fisiológico pero también psicoanalítico lacaniano. De hecho, las primeras heces de su propia hija recién nacida, tras ser enterradas por dos años, serán dispuestas sobre papel coreano para dar lugar a la obra Night Soiler no.90.2 (1990-1992).

Esta práctica de introducir partes del cuerpo en cajas de madera se verá continuada en otros trabajos performativos, como la serie Box Animal Face (1993-1994) de los años noventa: cajas con horadaciones, atadas con abrazaderas y barras fijadoras, concebidas como «almacenes de energía corporal», como él las denomina, aludiendo a principios taoístas, pero también influidas por los «cuerpos sin órganos» de Deleuze-Guattari, como su Bad Drawing (19921993). Con el cambio de milenio, Choi decide probar nuevos medios expresivos, esta vez de la mano de su hijo de cinco años y de los dibujos que este realizaba siguiendo un programa informático y que Choi simplemente se limita a se- 
leccionar y ampliar, como Animal Totem / Death Cult 0496, expuesta en las paredes del Hall del Rectorado.

El regreso a Corea en 2003 le confronta con la fuerte occidentalización aparente en la que se encuentra sumido el país, palpable en la introducción del inglés en el idioma coreano («konglish») y que le inspirará en su realización de una serie de textos con luces de neón en alfabeto coreano (hangeul) pero con transcripción fonética inglesa. Así, a la entrada de la Sala del Rectorado, el mensaje iluminado con luces de neón (90 x 120 cm) When you say No, You know something. When you know Something, communication is impossible (2010-2011), parece advertirnos ya acerca de barreras culturales insalvables que se esconden bajo la superficie de cordialidad, impidiendo una comunicación efectiva.

El texto aforístico de la obra en luces de neón con alfabeto coreano No Smart, No Fight (2010-2011), es retomado en otra pintura al óleo sobre lienzo en la que se recrea la pintura de paisajes taoístas, estampándose este mismo texto esta vez en alfabeto latino, en alusión a una máxima taoísta que nos dice que en realidad el más inteligente es el que evita la confrontación directa pretendiendo ignorancia. Otras obras, como la serie Ideographic Dissapearance (2015) se sitúan en la misma línea de relectura de elementos artísticos y filosóficos tradicionales de Asia Oriental.

La compleja relación de dependencia política, económica y cultural que ha unido a Corea del Sur con Estados Unidos desde los años cincuenta del pasado siglo, es explorada asimismo en relación con la división del país tras la guerra en la serie The Gift Exchange (2009) y Border Bounder (2011-2012), expuestas en la Sala Moreno Villa. Armas de guerra quedan recubiertas por objetos de consumo del mundo capitalista: zapatillas deportivas rotuladas con logos de marcas deportivas, todo unido formando una maraña con hilachos rojos, negros y cuerdas. En Border Bounder, $m \& m$ (2011-2012) tres rifles suspendidos en el aire, apuntando en diversas direcciones, con una diminuta escultura chamánica de la que a su vez cuelga una bolsa de chocolatinas m\&m explora la cara oculta de la deuda contraída con Estados Unidos tras la división del país.

En los últimos años Choi retoma la práctica apropiacionista con su serie Episteme sabotage, esta vez teniendo en su punto de mira a los propios coreanos que veneran el arte occidental sin entenderlo, solo por su valor en términos de capital simbólico y económico. En esta serie reproduce

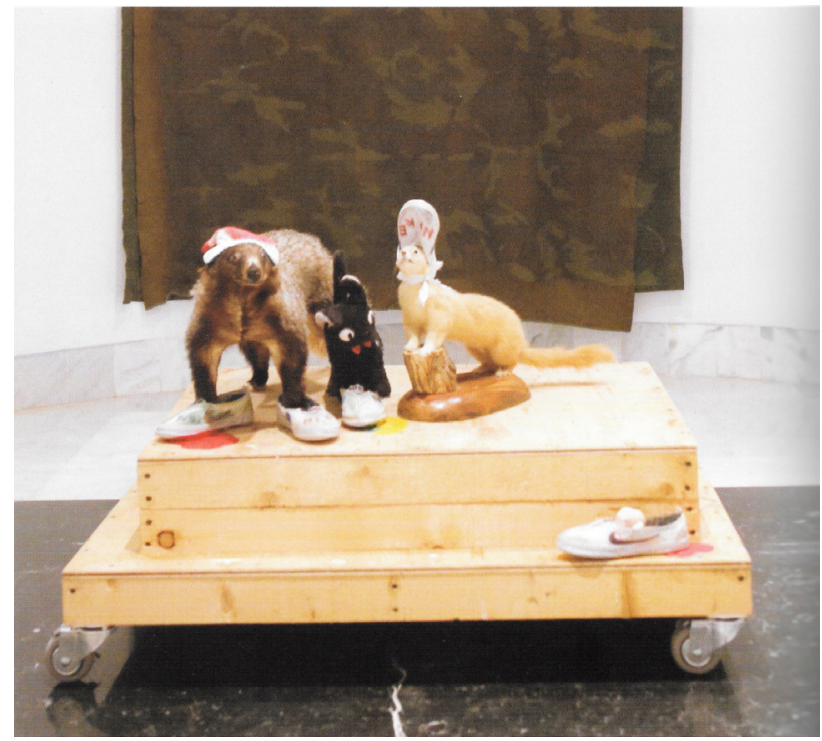

3. Queen Mother of the West: Olympia, 2016, técnica mixta, $100 \times 80 \times 64 \mathrm{~cm}$

miméticamente obras cumbre de la pintura occidental de artistas tanto clásicos como modernos (Leonardo da Vinci, Van Gogh, Picasso, Matisse, Motherwell, Bacon, etc.) y las profana añadiéndole pequeñas telas bordadas con mensajes a modo de cartelas o subtítulos irreverentes. Así, en Episteme Sabotage - Flower from East (2014) [2] la Olympia de Manet, es reproducida presentando una ligera modificación sobre el original, al portar la sirvienta de color un ramo de flores amarillo (en vez de blanco), tal vez en alusión a la propia etnicidad de esa «flor del Este» que podría ser el propio Choi.

Una obra reciente, expuesta en la sala de la muralla del Rectorado, Queen Mother of The West: Olympia (2016) [3], parece invitarnos a cerrar este periplo de geopolítica artística con sus múltiples bucles: sobre un pequeño pedestal rectangular de madera, pequeños mustélidos disecados, ataviados con zapatillas pintarrajeadas con logos deportivos, entre ellos un armiño, asociado a la realeza en Occidente, con una «victoriosa» zapatilla-visera ( $n$ i k e). Se evoca, así, irónicamente el cambio de la deidad taoísta que da título a la obra, «la reina madre de Occidente» (Xiwangmu), por la que de facto es en nuestros días (Olympia) el modelo de vida imperante en nuestras sociedades capitalistas de consumo globalizado.

Rosa Fernández Gómez 